\title{
Nanotechnologies for testing and diagnostics of materials, constructions and elements of engineering systems of buildings from them with fire retardant coatings. Part 1
}

\author{
V.V. Belozerov' (iD, A.I. Golubov' ${ }^{2}$ I.E. Kalchenko*, T.A. Nguyen ${ }^{3}$ iD, N.G.Topolsky ${ }^{2}$ \\ ${ }^{1}$ Don State Technical University, Rostov-on-Don, Russia \\ ${ }^{2}$ Academy of the State Fire Service of the Ministry of the Russian Federation for Civil Defense, \\ Emergencies and Disaster Management, Moscow, Russia \\ ${ }^{3}$ Fire Safety Institute, Hanoi, Vietnam \\ * Corresponding author: ivanrnd@mail.ru
}

\begin{abstract}
Introduction. The aim of the study was to optimize the quality control of fire retardant coatings (FRC) during their production and use. The results of a comparative analysis of the consequences of fires and their causes with the parameter of fire resistance of objects indicate that the number of fires and damage from them in buildings of the first degree of fire resistance is almost an order of magnitude smaller than in buildings of the second degree of fire resistance. Consequently, increasing the fire resistance of building materials and structures is the way to radically reduce fires and losses from them. Methods and materials. Based on a system analysis of existing fire protection technologies for building materials made of wood, metals, rubber and polymers, nanotechnologies were developed to determine the stability of samples with an FRC on the baro-electro-thermo-acoustic (BETA) analyzer and create their «images» for further diagnosis of their aging at the constructions and operation facility. The novelty of the study is protected by patents of the Russian Federation. Results and discussion. The obtained results consist in the refinement of computational algorithms for the FRC in the BETA analyzer, as well as in the development of a portable automated complex, which allows to determine the stage of «aging» of the FRC on these materials, and, consequently, their durability and update time. This conclusion is based, firstly, on the results of the development of a thermo-electro-dilatometer crucible for controlling liquid and viscous materials by the authors of the «float design», which will make it possible to control the FRC characteristics during their production, and secondly, to carry out express control after filling them in containers (polymer, metal, glass) without opening it and thirdly, due to the recognition of these «images» using thermo-electro-measurements of the FRC using special probes connected to a portable automated system. Conclusion. The results obtained make it possible to «arm» with portable automated systems not only construction and fire control authorities, but also manufacturers of emergency protection products. This will allow, according to the authors, to fundamentally solve the problems of quality and durability of FRC, but the main thing is to guarantee the stability of the protected materials and structures from them.
\end{abstract}

KEYWORDS: fire retardant coatings, degree of fire resistance, materials and structures, quality of fire retardant coatings, durability of fire retardant coatings, thermo-electro-acoustic method, heat conductivity, thermal diffusivity, heat capacity, aging of fire retardant coatings.

FOR CITATION: Belozerov V.V., Golubov A.I., Kalchenko I.E., Nguyen T.A., Topolsky N.G. Nanotechnologies for testing and diagnostics of materials, constructions and elements of engineering systems of buildings from them with fire retardant coatings. Part 1. Nanotechnologies in Construction. 2020, Vol. 12, no. 3, pp. 174-184. DOI: 10.15828/2075-8545-2020-12-3-174-184.

\section{INTRODUCTION}

$\mathrm{O}$ ver the past 15 years, every year in Russia [1], an average of 200 thousand fires have been recorded,

as a result of which about 13 thousand people die and almost as many are injured (Table 1).

(c) Belozerov V.V., Golubov A.I., Kalchenko I.E., Nguyen T.A., Topolsky N.G., 2020 
Table 1

Statistics of fires and their consequences in Russia

\begin{tabular}{|l|c|c|c|c|c|c|c|c|c|c|}
\hline \multirow{2}{*}{\multicolumn{1}{|c|}{ Indicators }} & \multicolumn{9}{|c|}{ Years } & $\begin{array}{c}\text { Average } \\
\text { value }\end{array}$ \\
\cline { 2 - 13 } & $\mathbf{2 0 0 3}$ & $\mathbf{2 0 0 5}$ & $\mathbf{2 0 0 7}$ & $\mathbf{2 0 0 9}$ & $\mathbf{2 0 1 1}$ & $\mathbf{2 0 1 3}$ & $\mathbf{2 0 1 5}$ & $\mathbf{2 0 1 7}$ & $\mathbf{2 0 1 9}$ & $\mathbf{2 1 5 . 6}$ \\
\hline Fires (thousand) & 239.2 & 229.8 & 212.6 & 187.5 & 168.5 & 153.5 & 145.6 & 132.4 & 471.1 & $\mathbf{1 2 8 9 0}$ \\
\hline Killed (people) & 19303 & 18412 & 16066 & 13946 & 12019 & 10601 & 9377 & 7782 & 8507 & 130 \\
\hline Injured (people) & 14032 & 13362 & 13688 & 13269 & 12516 & 11132 & 10920 & 9305 & 9474 & $\mathbf{1 1 9 6 6}$ \\
\hline $\begin{array}{l}\text { Damage from fires } \\
\text { (billion rubles) }\end{array}$ & 4.2 & 6.7 & 8.7 & 12.2 & 18.2 & 14.9 & 18.8 & 14.1 & 13.6 & $\mathbf{1 2 . 9}$ \\
\hline
\end{tabular}

The average value of the dead and injured is almost 25.000 Russians, which for the country's 145 million people more than 170 times (!) exceeds the requirements of a standard requiring a population safety of at least 0.999999 [2].

Moreover, the average annual percentage indicators of the causes of fires and the facilities at which they occurred are as follows [1]:

- residential buildings $-69.7 \%$ of fires, including $40.1 \%$ due to malfunction and violation of the rules for operating electrical appliances, gas and stove heating, due to careless handling of fire $-33 \%$, arson $-10 \%$, others $-13.6 \%$;

- vehicles $-14 \%$,

- public buildings $-4.2 \%$,

- production facilities $-2.1 \%$,

- warehouses $-0.9 \%$,

- agricultural facilities $-0.4 \%$.

Leaving the analysis beyond the scope of this article, the «reduction» in the number of fires and those affected by them, due to changes in accounting methods, and based on the «growth» of direct material losses, we agree with the following reasons for the deterioration of fire safety [3]:

Firstly, due to the «aging» of fixed assets and violation of technical regulations requiring periodic monitoring and restoration of safety parameters of facilities and equipment,

Secondly, due to the emergence of new fire hazardous technologies, machinery and equipment, requiring the use of adequate methods and means of diagnosis and suppression of their fire and explosion hazard,

Thirdly, the widespread use of flammable and combustible substances and materials in the home and at work, which increases the risk of accidents, explosions and fires.

Due to the fact that both in production and in everyday life, it is not always possible to do without the use of combustible materials, manufactures and products, methods for processing them with special means - paints and coatings, including nanostructured and polymerizable compositions that ensure their protection against operational impacts (moisture, temperature fluctuations, etc.) and in emergency situations (emergencies) - lightning, fires, explosions.

This article discusses fire retardant coatings (FRC), which are designed to protect building materials, constructions and products from them for engineering systems of buildings from the dangerous factors of fire (DFF).

The fact is that the existing methods and tools for diagnosing and monitoring the properties of FRC are differentiated (for steel constructions - fire safety standards 236-97; for wood - fire safety standards 251-98; for cables - fire safety standards 238-97, etc.), and do not use characteristics of protected materials and products, for an objective assessment of changes in their properties under the influence of emergency conditions, which gives rise to a mismatch between the actual fire hazard of the facilities and their calculations in declarations of their fire safety $[4,5]$.

This situation was formed because the tools for monitoring the operational stability of facilities, incl. using FRC, almost none. In connection with this, a scientific and technical problem arose - the development of methods and means of objective control, firstly, the quality of the FRC in their production, i.e. in the liquid phase, and secondly, and this is the main thing - diagnostics of the durability and fire resistance of products and constructions with FRC during their operation at various facilities (residential, administrative, commercial, etc.) $[5,6]$.

Various construction materials, structural elements and engineering systems, buildings in general, behave differently in emergency situations, and therefore, a need has arisen for a special indicator with which to compare the ability of objects to resist the effects of fire. As such an indicator, the concept of the degree of fire resistance of objects (from first to fifth) was introduced, which are international fire-technical characteristics that differ in times during which materials, constructions and buildings can resist DFF [7]. 
However, such a latent form of the fire resistance parameter does not allow their use in the equations of Semenov, Zeldovich and Frank-Kamenetsky, on which the theory of combustion and explosion is based, and therefore, it became necessary to develop new methods and means of diagnostics and control the stability of building materials and constructions from them, including with FRC, which would allow for the objective control of their design and operational stability, including in emergency situations $[6,8]$.

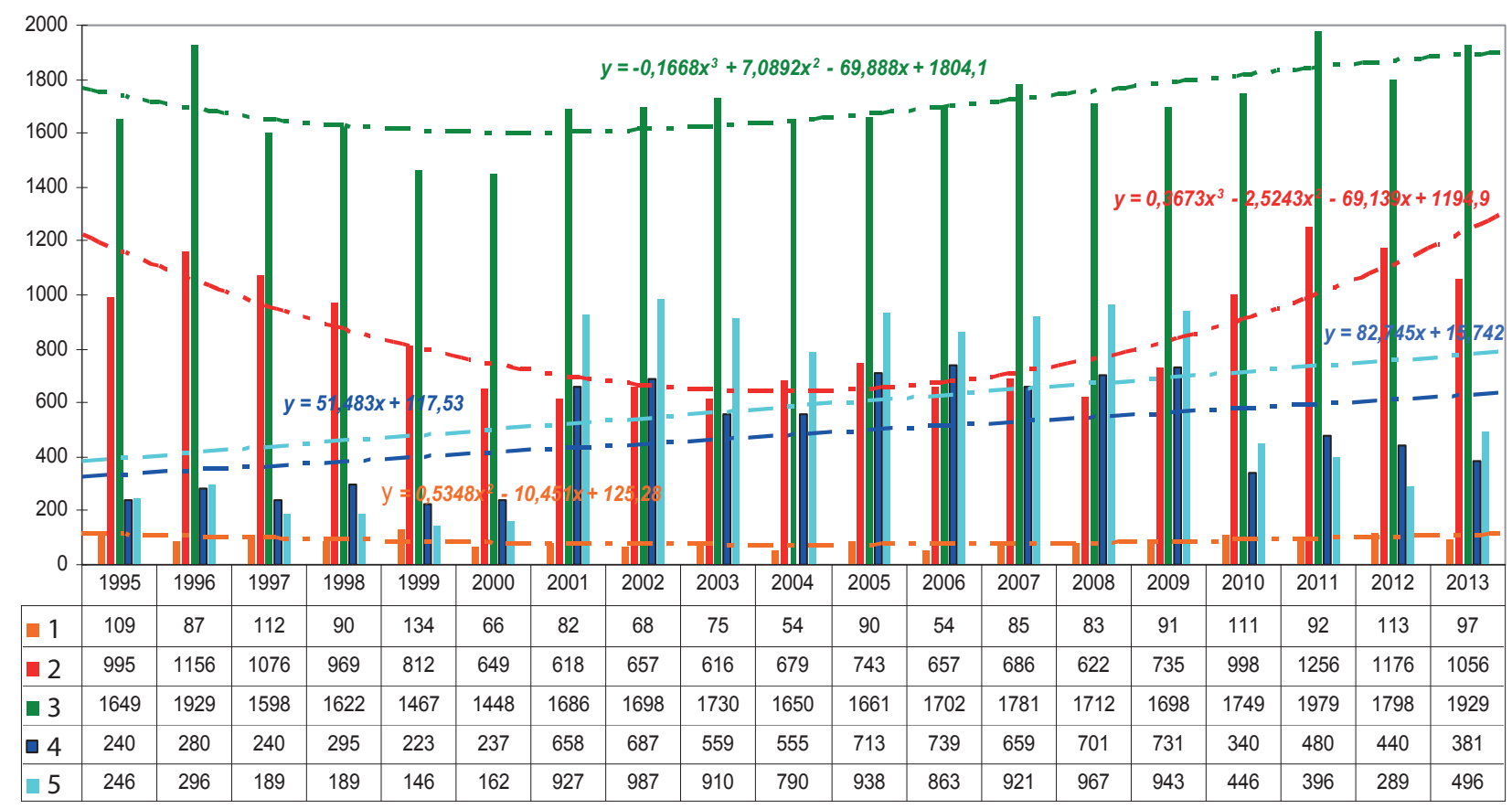

Fig. 1. Histograms of the number of fires in buildings $I-V$ degrees of fire resistance

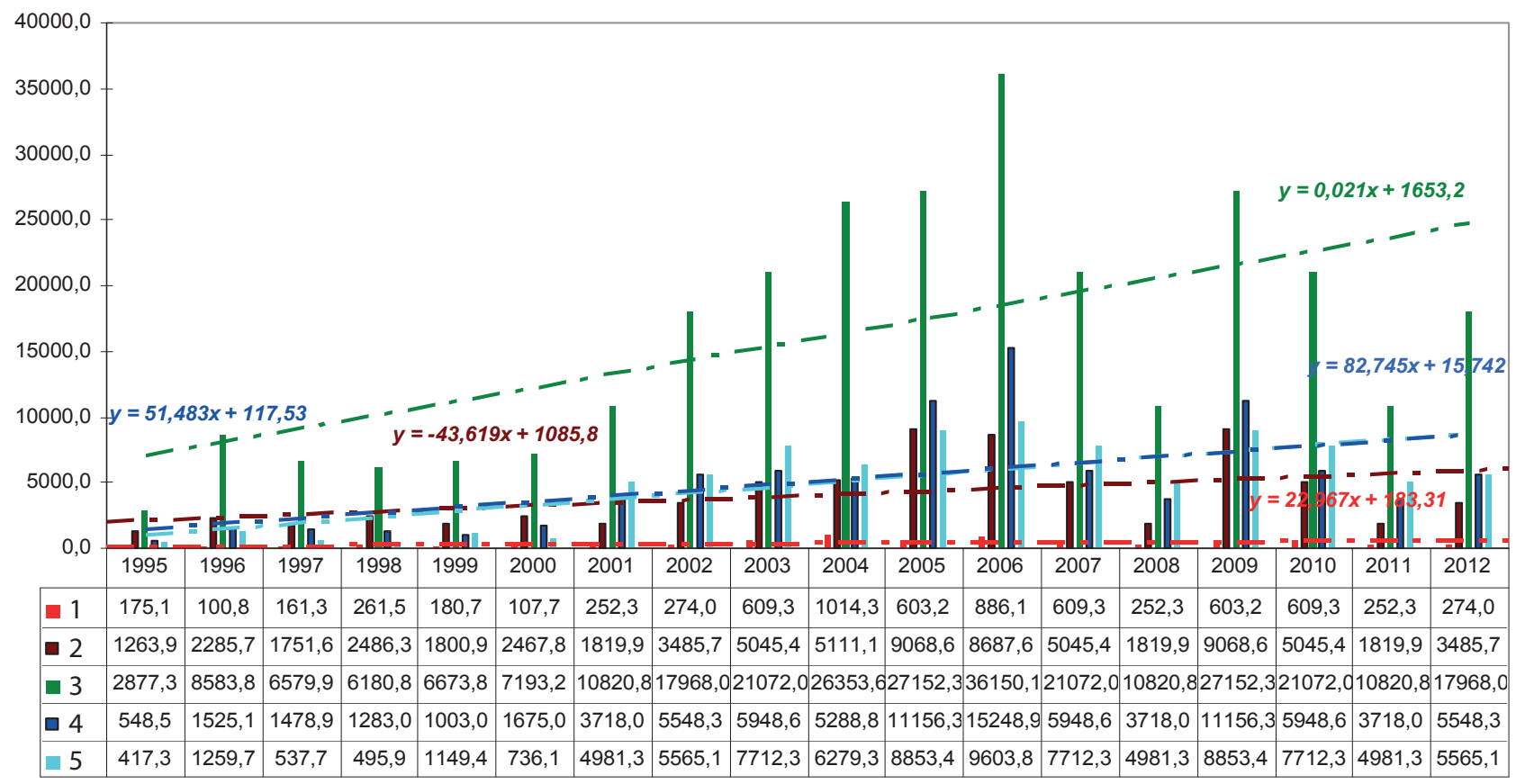

Fig. 2. Histograms of losses from fires in buildings of $I-V$ degree of fire resistance (thousand rubles) 


\section{PROBLEMS OF USING NANOMATERIALS AND NANOTECHNOLOGIES IN CONSTRUCTION}

The results of a comparative analysis of the consequences of fires (death, injuries, material losses, destroyed and damaged areas) and their causes with the fire resistance parameter of objects show (Figs. 1 and 2) that the number of fires and damage from them in buildings of the 1st degree of fire resistance is practically an order of magnitude less than in buildings of the II degree of fire resistance. Consequently, increasing the fire resistance of building materials and constructions is the way to radically reduce fires and losses from them $[4,8]$.

\section{METHODS AND MATERIALS}

As our research and development has shown, the most acceptable method for testing any building materials is the method and complex of baro-electro-thermo-acoustometry (BETA), which implements a combined influence on a sample of material (Figs. 3 and 4) [6,8].

The BETA analyzer allows you to get all the necessary characteristics, as well as to determine the existing and additional indicators of their fire hazard, because registers and calculates the $38^{\text {th }}$ parametric vector function of the «life cycle» (VFLC) of the material under operating conditions - F [P, T, mi, $l_{i}, \rho_{i}, \lambda_{i}, a_{i}, C p_{i}, C v_{i}, \beta_{i}, \gamma_{i}, \zeta_{i}, h_{i}$, $\chi_{i}, \psi_{i}, H_{i}, F o_{i}, B_{i}, E_{i}, K_{i}, G_{i}, v_{i}, \rho g \bullet l / E_{i}, \sigma_{i},\left|Z_{i}\right|, C_{i}(R), \operatorname{tg} \sigma_{i}$, $\left.\varepsilon_{i}, \mu_{i} ; \mu i \cdot l_{i}^{2} / \sigma_{i} t, L / R_{i} t, \varepsilon_{i} \cdot \sigma / t, C / \sigma_{i} t, N a_{i}, U_{i}, G_{i}, \eta_{i}\right)[9,10]$.

The BETA analyzer was created as part of the START program project No. $5823[10]$ and, in contrast to the well-known synchronous thermal analysis devices (STA), which use linear modes of temperature and pressure changes, uses the adaptive thermo-baro-cycle method (ATBC), working stepwise (Fig. 5) [11].

This makes it possible to obtain «quasistationary» sections (temperature and pressure) in the vicinity of «singular points» (phase transitions, etc.), and, therefore, correctly calculate the thermodynamic characteristics of the material, which ensures the reliability of the results obtained, and also made it possible to set solve the problem of «accelerated aging of materials» in operating conditions [10, 11].

To implement the ATBC method, a thermo-cryostat-electric furnace was developed (Fig. 6), in which the heating and cooling processes were combined by using a nichrome electric heater, and as an SF6 cooler (R-510) in each of 8 sections, controlled by a controller (TREI5B-05), which made it possible to ensure «quasistationary

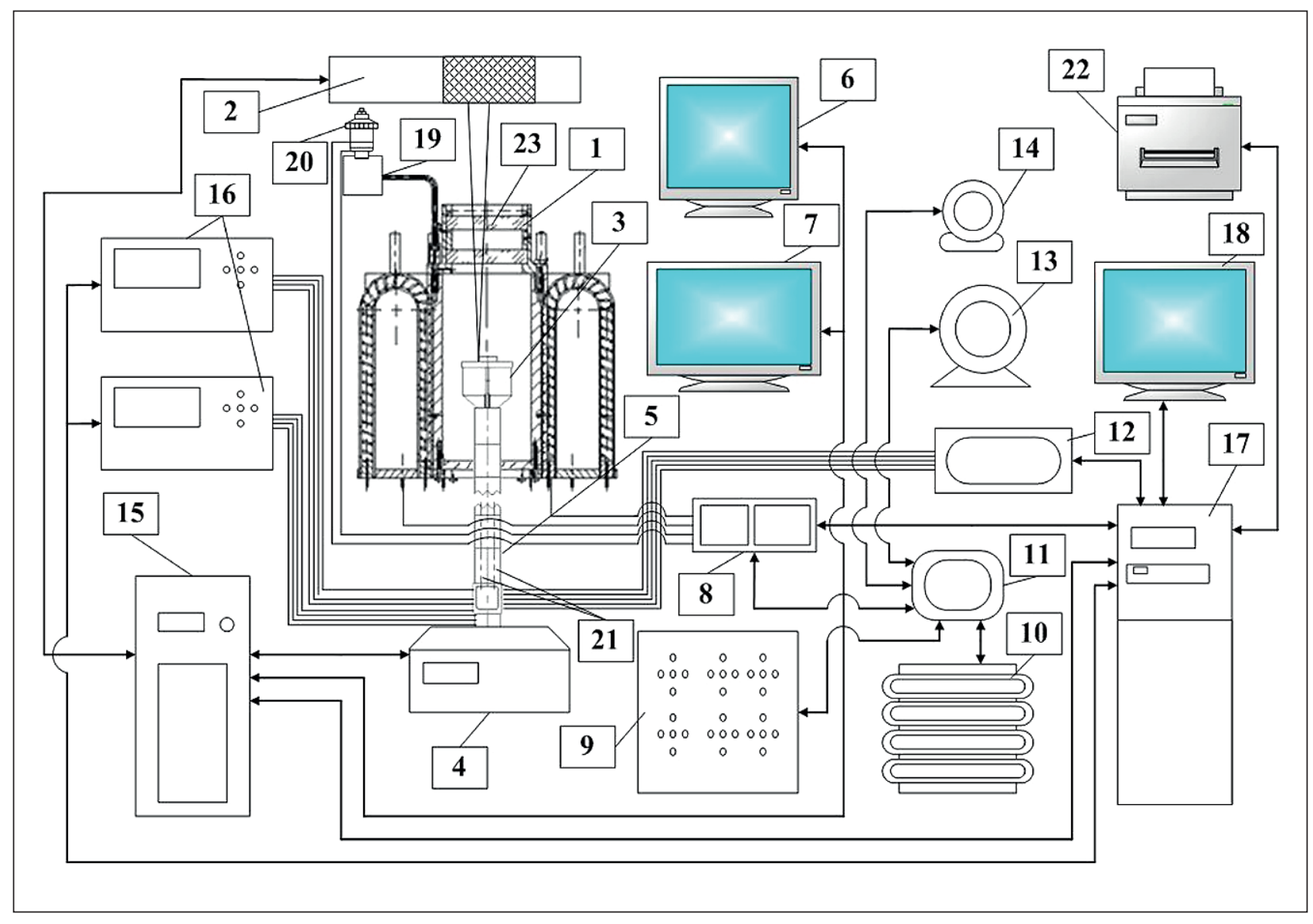

Fig. 3. Block diagram of a BETA analyzer 


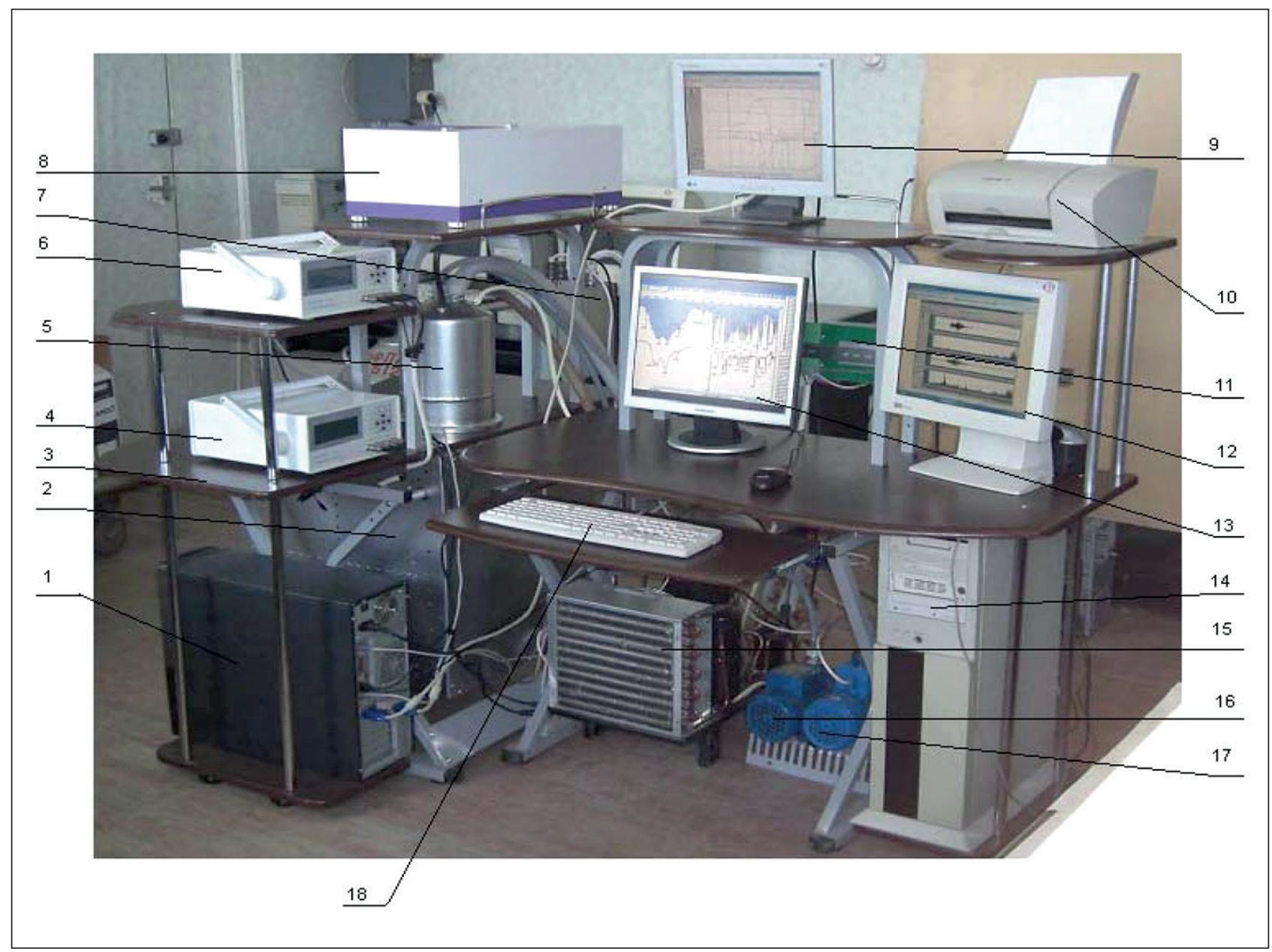

\section{Fig. 4. Appearance of the BETA analyzer}

1 - file server (FS); 2 - Gravioacoustic-electrometric module (GAEM); 3 - subject table (PS); 4 - meter of immitance E7-20; 5 - modified thermocryostat-electric furnace (TKSEF); 6 - meter of immitance E7-20; 7 - control modules TKSEF, compressor and foreline pump (ISM); 8 - FT-801 IR Fourier spectrometer; $9-1^{\text {st }}$ FS monitor; 10-color printer; 11 - master module M902E MFC «TREI-5V-05»; 12 - monitor workstation (PC); $13-2^{\text {nd }}$ FS monitor; 14 - workstation (PC); 15 - reverse heat/cold circuit (RCT); 16 - forevacuum pump; 17 - compressor; 18 - operator workstation with keyboard and mouse

temperature sections» with high accuracy. In a similar way (a compressor and a fore-vacuum pump with electromagnetic valves), «quasistationary pressure sections» were ensured $[10,11]$.

In addition to accelerated aging of the material sample during testing, this approach made it possible to modify and synchronize ten different methods of thermal analysis and one metrological method, namely:

- thermobarogravimetry (TBG), implemented by WZA-224CW magnetometric scales (Sartorius company) with a built-in $200 \mathrm{~g}$ calibration weight controlled by a computer, which allows them to be calibrated with restoring the tare mass (crucible of a thermo-electrodilatometer on a thermo acoustic rod-waveguide - TED TARW) at any time (which is especially important with thermo-baro-cycles), with a resolution of measuring the mass of a sample (up to $50 \mathrm{~g}$ ) $-m$ at 10 micrograms, and in double-precision mode - differential thermo-barogravimetry (DTBG) with a resolution of $\mathrm{d} m / \mathrm{d} T-$ up to 1 micrograms /grad [9,10];

- thermobarodilatometry (TBD) and differential thermobarodilatometry DTBD), which is implemented by a crucible (Fig. 7 «a») with a thermoelectro-dilatometer (TED) and two immitance meters (E7-20) controlled by a computer that calculates the linear size of the sample $l$ and its changes $-\mathrm{d} l / \mathrm{dT}$ and $\mathrm{d} l / \mathrm{dP}$, regardless of the type of material (dielectric, conductor, semiconductor), due to the design of the TED and the presence of its exact parameters (diameter, height from the bottom to the cover, thickness of the movable cover), according to a unified equivalent circuit and general mathematical model (1) $[9,10]$. 


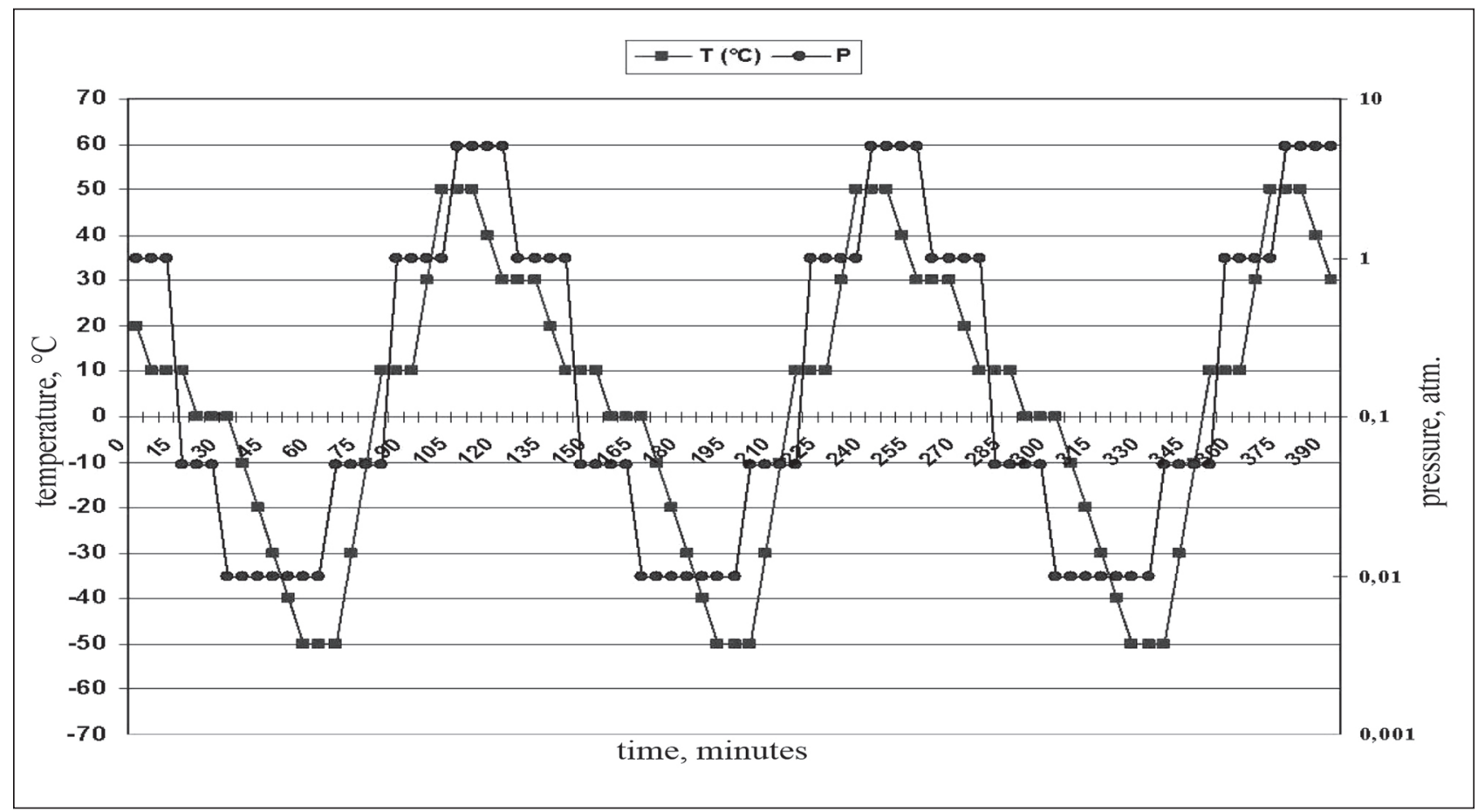

Fig. 5. Adaptive Thermo-Baro Cycle

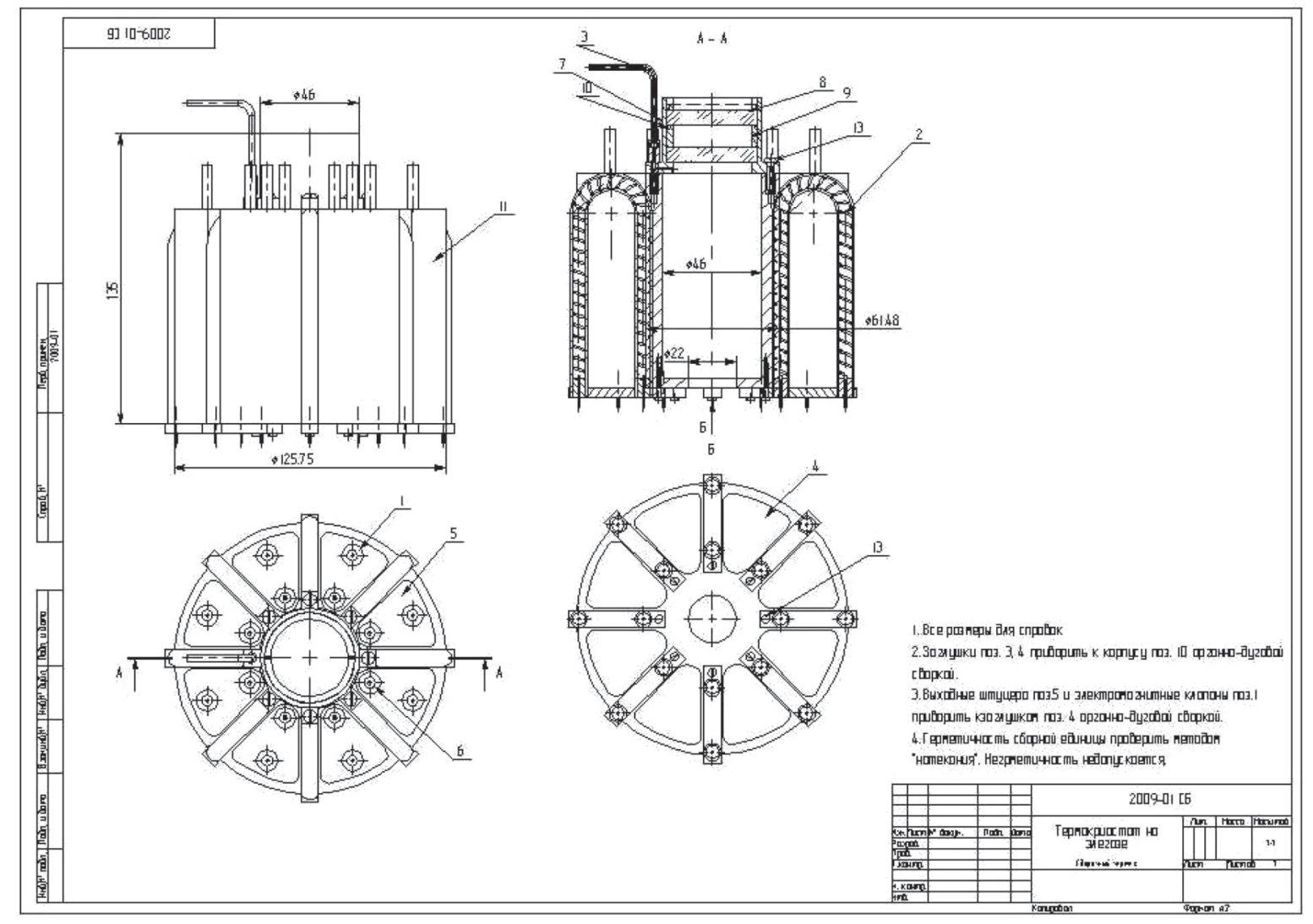

Fig. 6. Assembly drawing of a thermo-cryostat-electric furnace (TCSEF) 
a)

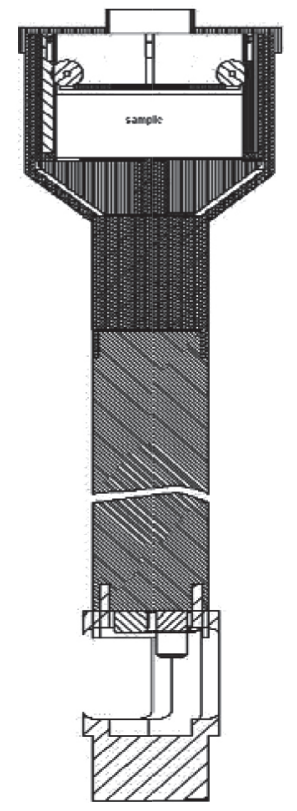

b)

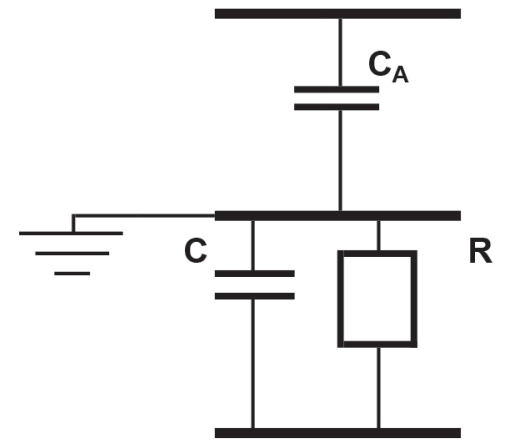

Fig. 7. Crucible thermo-electro-dilatometer (TED) and its equivalent circuit

$$
\left\{\begin{array}{l}
\ell_{A}=\frac{\varepsilon_{A} \cdot \varepsilon_{0} \cdot \pi D^{2}}{4 C_{A}} \\
\ell=h_{T E D}-h_{m p}-\ell_{\mathrm{A}} \\
\varepsilon=\frac{4 \ell \cdot C}{\varepsilon_{0} \cdot \pi D^{2}} \\
r=\frac{R \cdot \pi D^{2}}{4 \ell}
\end{array},\right.
$$

where $l$ is the linear size of the sample in the TED; $D$ is the diameter of the movable plate TED; $\varepsilon_{0}$ is the dielectric constant of vacuum; $C$ is the capacity between the movable lining and the bottom of the TED; $l_{\mathrm{A}}$ is the distance from the mobile plate to the TED cover; $C_{\mathrm{A}}$ is the capacity between the movable cover and the TED cover; $\varepsilon_{\mathrm{A}}$ is the dielectric constant of the air between the movable plate and the TED cover; $R$ is the resistance of the sample; $h_{\mathrm{TED}}-$ TED height (from the bottom to the cover); $h_{\mathrm{mp}}$ is the thickness of the movable plate.

- thermo-baro-densimetry (TBD), which is a new method of thermal analysis, because calculates the density of the sample $-\rho$ and its changes $-\mathrm{d} \rho / \mathrm{dT}$ and $\mathrm{d} \rho / \mathrm{dP}$ (according to changes in the mass and volume of the sample), due to the synchronization of thermogravimetry and thermodilatometry (TG, DTG, TD and DTD), which have not been matched to date in any devices of thermal analysis [10];
- differential scanning calorimetry (DSC) and the calibrated heat flux method (practically according to GOST 25380-2014), implemented in the same TED using the «reference section with air medium» (Fig. 8), which, in addition to thermal conductivity, $\lambda$, thermal diffusivity, $\mathrm{a}$ and the specific heat of the sample - $\mathrm{C}$ (at constant temperature and at constant pressure), determine all caloric and thermal coefficients: $\xi=\mathrm{dQ}_{\mathrm{T}} / \mathrm{dV}, \mathrm{h}=\mathrm{dQ}_{\mathrm{T}} / \mathrm{dP}, \chi=$ $\mathrm{dQ}_{\mathrm{p}} / \mathrm{dV}, \psi=\mathrm{dQ}_{\mathrm{v}} / \mathrm{dP}, \beta=-(\partial \mathrm{V} / \partial \mathrm{P}) / \mathrm{V}, \gamma=(\partial \mathrm{P} / \partial \mathrm{T}) / \mathrm{P}$, thanks to the adaptive thermo-baro cycles (Fig. 5) and the design of the TED creating calibrated heat fluxes into the sample ( $\mathrm{Q}$ and $q$ ), because heat dissipation by zirconia ceramics of TED walls $(1.3 \mathrm{~W} / \mathrm{m} \cdot \mathrm{K})$ is two orders of magnitude lower $(1 \%)$ than molybdenum $(118-138 \mathrm{~W} / \mathrm{m} \cdot \mathrm{K})$ in the operating temperature range (heat dissipation and error can be reduced to $0.1 \%$ if the TED is made of nanostructured or wollastonite ceramic [12] having a thermal conductivity of $0.035-0.5 \mathrm{~W} / \mathrm{m} \cdot \mathrm{K}$ );

- differential-barothermic analysis (DBTA) - implemented in the same TED as a «reference section of the air» (vacuum or air as a reference), as a result of which the enthalpy from the heat balance equation is correctly determined: $\Delta \mathrm{mdH} / \mathrm{dt}+\lambda(\mathrm{To}-\mathrm{Tm})=\mathrm{mC}_{\mathrm{p}} \Delta \mathrm{T}[5]$;

- electrometry, incl. dielectric analysis (DEA) and electromagnetic analysis (EMA), implemented by TED and emittance meters (E7-20), controlled by a computer that calculates the functions of the dielectric $(\varepsilon)$ and magnetic permeability of the sample $(\mu)$, measuring ca- 


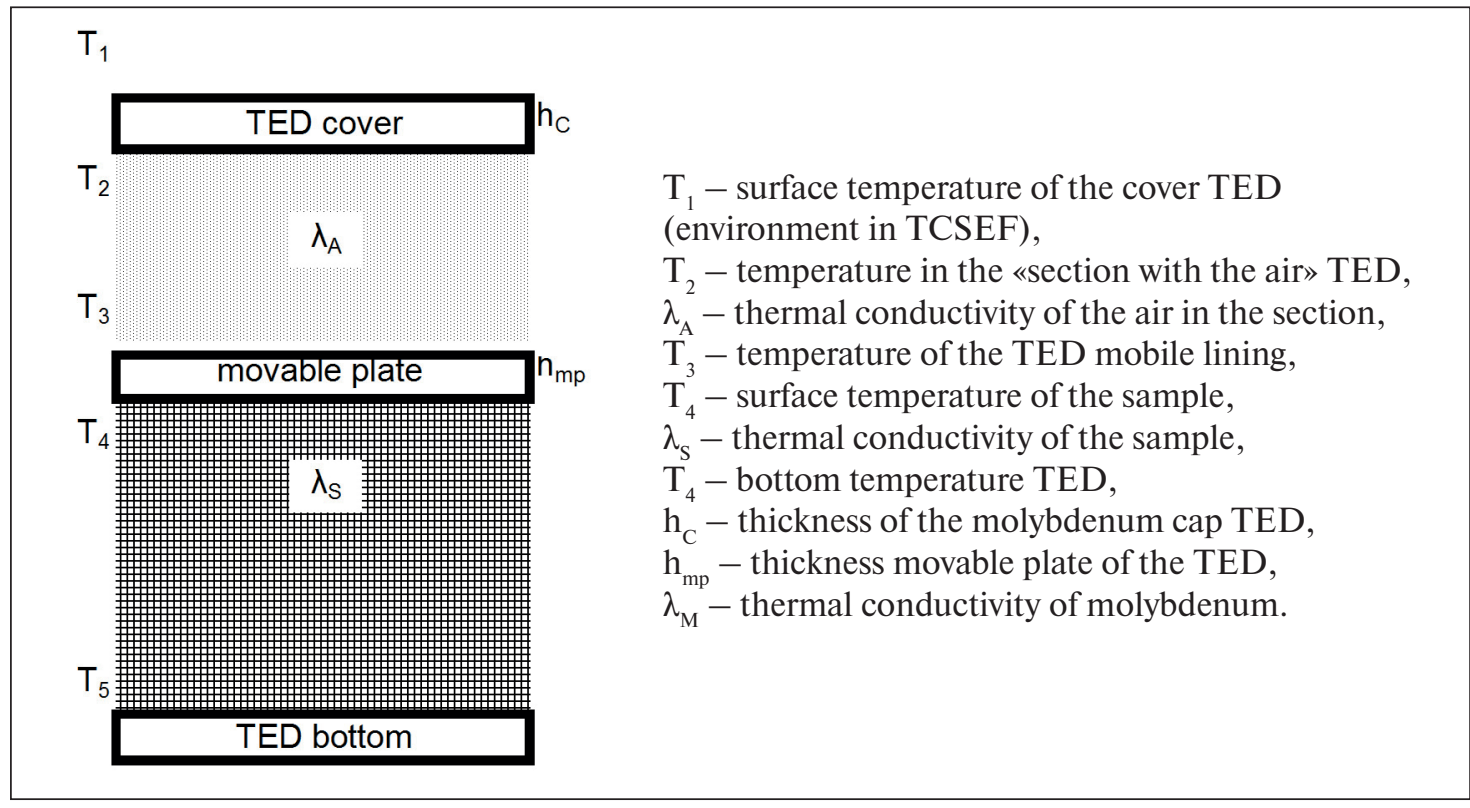

Fig. 8. Scheme for measuring heat flux and thermal conductivity of a sample in a TED

pacitance, complex resistance and finding the extremes of the tangent loss angle in the range $25-10^{6} \mathrm{~Hz}$, after which, solving the impedance equations, presents them in $\mathrm{a}$ «3-dimensional combination» of coordinates $(\mathrm{T}, \mathrm{P}, \omega)$, calculating the criteria of homo-chronic at the extremes points $\left(\mathrm{Ho}_{3}=\varepsilon \rho / \mathrm{t}, \mathrm{Ho}_{2}=\mu \mathrm{l}^{2} / \rho \mathrm{t}\right.$ and $\left.\mathrm{Ho}_{5}=\mathrm{C} / \mathrm{Gt}\right)[13]$;

- dynamic and thermal mechanical analysis (DMA and TMA) - implemented using data from the LDP and DBTA and the connection $\beta$ with the bulk modulus ( $\mathrm{K}=$ $1 / \beta)$, which are used to calculate the remaining moduli of elasticity $\mathrm{E}=\mathrm{P} \cdot 1 / \Delta \mathrm{l}, \mathrm{G}=3 \mathrm{E} /(9-\beta \cdot \mathrm{E}), v=(\mathrm{E}-$ $2 \mathrm{G}) / 2 \mathrm{G}, \mu \mu=\mathrm{G}, \lambda \lambda=(1-2 \beta \cdot \mu) / 3 \beta$, as well as the second similarity criterion for elastic strains, equal to $\rho \mathrm{gl} / \mathrm{E}$, and the tangent of the angle of mechanical losses [6, 10];

- acoustic emission analysis (AE), implemented by 2 AE-sensors mounted on 2 thermo-acoustic rod-waveguides located in the ceramic «leg» of the TED, the segments of which form the «bottom» in the TED in contact with the sample, which they are connected to the ALine-32 PCI8 module («Interunis» company), which determines, through two independent channels, the flow intensity (quantity per unit time) of $\mathrm{AE}$ acts $-\mathrm{dNa} / \mathrm{dt}$, their total number $-\mathrm{Na}$, amplitudes - U, and also the spectral composition of radiation $-\mathrm{G}(\mathrm{f})$, which allows us to study the kinetics of changes in the sample and the diagnosis the earliest stages of the processes, as well as to calibrate measuring circuits AE, switching one of the sensors in a radiation mode from a reference oscillator [5, 14];

- IR Fourier spectrometry of the products of destruction and combustion in the working volume of the TCSEF through a quartz window in it (Figs. 3 and 7) using the FT-801 IRF-spectrometer [15], allowed real-time de- termination of the smoke formation coefficient of these products and their toxicity according to the formulas V.N. Pavlova [16, 17];

- metrological certification of the measuring channels of the BETA analyzer using thermodynamic acoustic emission etalons (TDAE «droplets» of mercury and water sealed in the TED bottom), which have without hysteretic characteristics of phase transitions of the first kind, that allow you to calibrate measuring channels during testing, which was protected by a patent of the RF [18].

The exact values of the sample parameters obtained in this way allow us to determine its similarity criteria (Fourier number $-\mathrm{Fo}=\mathrm{a} \cdot \mathrm{t} / \mathrm{1}^{2}$ and Biot number $-\mathrm{Bi}=\alpha \cdot 1 / \lambda$ ) and construct curves of their changes in temperature and time for registration and identification nano-, micro- and microstructural changes in the sample, including with its «aging» $[8,9]$.

\section{RESULTS AND DISCUSSION}

The developed technique for any FRC differs from the BETA-analysis of solid samples [10], both by the preparatory stage [8] and by new algorithms for calculating the FRC parameters.

At the preparatory stage, two identical cylindrical samples are made of steel, wood, rubber and polymer, after which their dimensions and weight are fixed, and one of the cylinder bases is covered with FRC in accordance with the technical specifications on them [8].

After drying (polymerization), samples with FRC are weighed to determine the mass of FRC at each, and the next stage begins - «express analysis of the sample». 


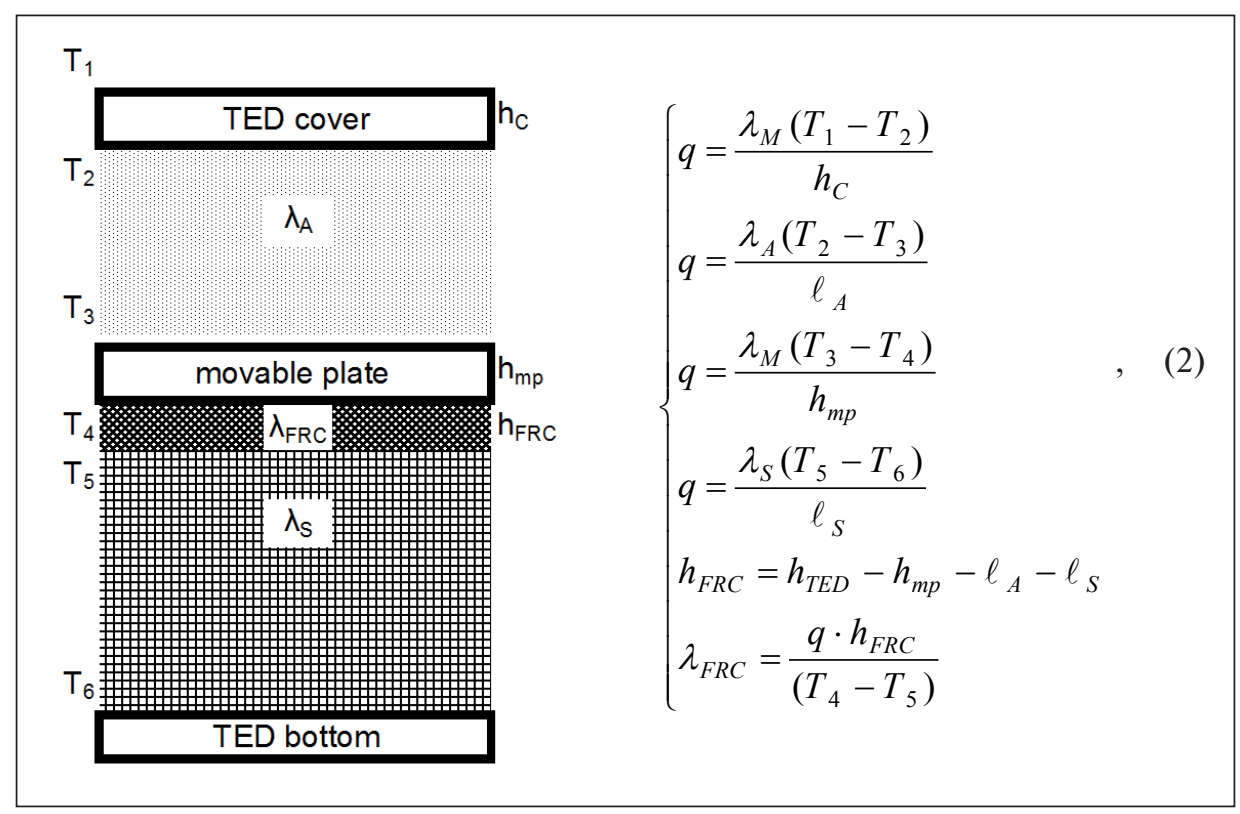

where $l_{O}$ is the linear size of the protected sample (1); $h_{F R C}-$ thickness of the FRC; $T_{1}$ is the surface temperature in the TKSE (of the TED cover); $T_{2}$ is the temperature in the «section with the air medium» TED, $\lambda_{\mathrm{A}}$ is the thermal conductivity of the air in the section, $\mathrm{T}_{3}$ is the temperature of the movable plate of the TED, $\mathrm{T}_{4}$ is the surface temperature of the FRC, $\lambda_{\mathrm{FRC}}$ is the thermal conductivity of the $\mathrm{FRC}, \mathrm{T}_{5}$ is the surface temperature of the sample, $\mathrm{T}_{6}$ is the bottom temperature of the TED, $h_{C}$ is the thickness of the molybdenum cover of the TED, hmp is the thickness of the movable plate of the TED, $\lambda_{\mathrm{M}}$ is the thermal conductivity of molybdenum, and $\lambda_{\mathrm{S}}$ is the thermal conductivity of the sample.

Fig. 9. Scheme of measuring a sample with FRC in TED

Express analysis consists of placing of the sample in a TED and «running» the first samples with linear cooling / heating from minus $60^{\circ} \mathrm{C}$ to plus $200^{\circ} \mathrm{C}$ in TCSEF in vacuum $(0.01 \mathrm{~atm})$, with the determination of the VFLC of the sample protected by the FRC (Fig. 9), as well as the solution of the system of Fourier (2) equations for determining the thermal conductivity $-\lambda_{\mathrm{FRC}}$ and thickness $-\mathrm{h}_{\mathrm{FRC}}$ of the FRC:

Further, the pressure in the TCSEF rises to atmospheric and at a temperature of plus $200^{\circ} \mathrm{C}$, exposure is carried out for 5 minutes (to determine the change in the combustibility group of the sample with FRC by weight loss), after which heating continues to a temperature of plus $835^{\circ} \mathrm{C}$. In this case, not only the actual times of fire resistance of the samples are recorded [19], due to the «swelling» of the FRC (change in its thickness and thermal conductivity coefficient), but also are monitored the vector-functions of life-cycle of the samples themselves under the protection of the FRC, the critical values of which make a conclusion about the effectiveness of the FRC for each sample of steel, wood, rubber and polymer [8].

The final stage - «aging of samples» - according to test plans for «second samples» (formed according to the results of «express analysis» of the first samples) with FRC applied to them, according to adaptive thermo-baro-cycles, with the provision of quasi-isothermal and quasi- of isobaric regimes in the vicinity of the obtained singular points, for refinements the «VFLC aging of FRC» on the samples, before damage to the FRC [8, 19].

\section{CONCLUSION}

The proposed approach not only most fully reflects the characteristics and behavior of the FRC during the production and operation at the facilities, but also complements the well-known methods for determining fireretardant efficiency, which are reflected in the relevant regulatory documents [22-24], creating an «FRC image» for subsequent identification of the stages its «aging», and therefore the determination of the time of its updating at any objects of supervision $[8,25]$.

Moreover, the development of a «float design» of a thermo-electro-dilatometer crucible for monitoring liquid and viscous materials will make it possible to control characteristics of the FRC during their production, including express control after packaging them in containers (polymer, glass, metals) without opening it, which guarantees their quality when used at objects of protection $[26,27]$. 


\section{REFERENCES}

1. Federal database «FIRES» [Electronic resource]. http://vniipo.ru/institut/informatsionnye-sistemy-reestrybazy-i-banki-danny.

2. GOST 12.1.004 Fire safety. General requirements. Moscow: Ed. standards, 1992. (in Russian)

3. Belozerov V.V., Zaguskin S.L., Prus Yu.V., Samoilov L.K., Topolsky N.G., Trufanov V.N. Classification of objects of increased danger and probabilistic-physical models for assessing their stability and safety. Life Safety. 2001. No. 8. P. 34-41. (In Russian).

4. Kalchenko I.E. An analysis of the objectivity of assessing fire resistance and the effectiveness of fire protection of structures of infrastructure for various purposes. Theoretical and applied aspects of modern science. 2014. No. 3-1, pp. 64-72. (In Russian).

5. Belozerov V.V., Topolsky N.G., Golubov A.I. Multiparameter assessment of the properties and fire and explosion hazard characteristics of liquid substances and materials. Annual International Scientific and Technical Conference Security Systems. - SB 2012: materials of the $21^{\text {st }}$ scientific and technical. conf. Moscow: AGPS of the Ministry of Emergencies of the Russian Federation, 2012. pp. 30-31. (In Russian).

6. Belozerov V.V., Marchenko A.V., Prus Yu.V. BETA-analysis in the diagnostics of safety and strength of structural materials. Annual international scientific and technical conference Security systems. - SB 2008: Mater. $17^{\text {th }}$ Int. Conf. Moscow: AGPS of the Ministry of Emergencies of the Russian Federation, 2008. pp. 54-57. (In Russian).

7. Belozerov V.V., Fornicious N.P., Kalchenko I.E., Oleinikov S.N. Philosophical and Philological Aspects of Security. International Journal of Experimental Education. 2016. No. 2 (Part 1), pp. 170-175.

8. Prus Yu.V., Golubov A.I., Kalchenko I.E. Thermo-electro-acoustic method and system for diagnosing the quality and durability of fire-retardant coatings // Electronics and Electrical Engineering. 2016. No. 1. pp. 146-160. DOI: 10.7256/2453-8884.2016.1.21075. (In Russian).

9. Belozerov V.V. The vector-function of the life cycle of materials. Fundamental and applied aspects of new highly efficient materials: collection of articles. Proceedings of the II All-Russian Scientific Internet Conference with International Participation. Kazan: IP Sinyaev D.N., 2014, pp. 11-13. (In Russian).

10. Belozerov V.V. Automated system for testing materials of the electrical and electronic industries with control of their fire hazard: PhD. thesis. Moscow: ASFS of the Ministry of Emergencies of the Russian Federation, 2008. (In Russian).

11. Belozerov V.V., Bosy S.I., Mazurin I.M. Adaptive thermal cycling method and system for its implementation. Application for invention No. 2009121080, publ. 10.12.2010, Bull. Number 34. (In Russian).

12. Alekseev M.K., Bizin I.N., Gorchakova L.I. and others. A method of producing ceramic products based on wollastonite. Patent of the Russian Federation for invention No. 2524724, publ. 08/10/2014 Bull. Number 22. (In Russian).

13. Barefoot S.I., Buylo S.I. On the synchronization of thermal analysis with acoustic emission and electrometry. Electronics and Electrical Engineering. 2016. No. 1. P. 1-20. (In Russian).

14. Belozerov Vl.V., Buylo S.I., Prus Yu.V. Combined thermogravimetric and acoustic emission method for determining the stages of thermal degradation of substances and materials and a device for its implementation. RF Patent for invention No. 2324923, publ. 05/20/2008, Bull. Number 14. (In Russian).

15. Ezhevskaya T.B., Bagels A.V. The history and prospects of the use of infrared FT-801 infrared Fourier spectrometers in forensic laboratories under the Ministry of Justice of Russia. Theory and Practice of Forensic Expertise. 2008, No. 1 (9). pp. 219-227. (In Russian).

16. GOST 12.1.044 Fire and explosion hazard of substances and materials. The nomenclature of indicators and methods for their determination. Moscow: Standartinform, 2018. (In Russian).

17. Pavlov V.N. The generalized equation of dependence concentration (dose) - time-effect of the harmful effects of chemicals on the body. Annual international scientific and technical conference Security Systems SS-97. Moscow: MIPB Ministry of Internal Affairs of the Russian Federation, 1997, pp.80-81. (In Russian).

18. Belozerov V.V., Bosy S.I., Buylo S.I., Prus Yu.V., Udovichenko Yu.I. The method of thermodynamic acoustic emission standardization and its system implementing. RF Patent for the invention No. 2399910, publ. 09/20/2010, Bull. Number 26. (In Russian).

19. Kalchenko I.E. Simulation methods for assessing the quality of fire retardant coatings. Technosphere Safety Technologies. 2015. No. 1 (59). URL: http://academygps.ru/ttb.

20. GOST R 53295-2009 Fire protection means for steel structures. General requirements. Method for the determination of fire-retardant efficiency. Moscow: Standartinform, 2018. (In Russian).

21. GOST R 53311-2009 Fireproof cable coatings. Methods for determining flame retardant efficiency. Moscow: Standartinform, 2018. (In Russian). 
22. GOST R 53293-2009 Fire hazard of substances and materials. Materials, substances and means of fire protection. Identification by thermal analysis methods. Moscow: Standartinform, 2018. 23 p. (In Russian).

23. Golubov A.I. The method of thermoanalytical determination of the main characteristics of flammable liquids. Electronics and Electrical Engineering. 2018. No. 1. pp. 1-7. (In Russian).

24. Golubov A.I. Thermoelectroacoustic method for the analysis of liquid media and fire retardant coatings. Student Scientific Forum-2017: Materials of the IX International Student Scientific Conference. URL: http://scienceforum. $\mathrm{ru} / 2017 /$ article/2017030353. (In Russian).

25. Belozerov V.V., Lukyanov A.D., Obukhov P.S., Abrosimov D.V., Lubavsky A.Yu., Belozerov Vl.V. The method of rapid analysis of liquid packaged products and installation for its implementation. Patent for invention RU 2696810, publ. 08/06/2019, Bull. 22. (In Russian).

\section{INFORMATION ABOUT THE AUTHORS}

Valery V. Belozerov, Dr. Sci. (Eng.), Associate Professor, Professor of Department «Automation of Production Processes», Don State Technical University, Rostov-on-Don, Russia, ORCID: 0000-0001-6999-7804, e-mail: safeting@mail.ru

Andrey I. Golubov, Applicant, Department of Automated Systems and Information Technologies, State Fire Service Academy of the Ministry of Emergencies of Russia, Moscow, Russia, e-mail: andreasen@yandex.ru

Ivan E. Kalchenko, Applicant, Department of Automated Systems and Information Technology, State Fire Service Academy of the Ministry of Emergencies of Russia, Moscow, Russia, e-mail: ivanmd@mail.ru

Tuan A. Nguyen, Cand. Sci. (Eng.), Associate Professor, Fire Safety Institute, Hanoi, Vietnam, ORCID: 0000-0002-0230-9066, e-mail: tuan_moskva@mail.ru

Nirjkolai G. Topolsky, Dr. Sci. (Eng.), Professor, Professor of the Department of Automated Systems and Information Technologies, State Fire Service Academy of the Ministry of Emergencies of Russia, Academician of the Russian Academy of Natural Sciences, Moscow, Russia, ORCID: 0000-0002-0921-4764, e-mail: ntopolskii@mail.ru

\section{Author declare the absence of any competing interests.}

Received: 18.04.2020.

Revised: 22.05.2020.

Accepted: 04.06.2020. 